www.jmscr.igmpublication.org Impact Factor 5.244

Index Copernicus Value: 5.88 ISSN (e)-2347-176x ISSN (p) 2455-0450 crossref DOI:_http://dx.doi.org/10.18535/jmscr/v4i6.50

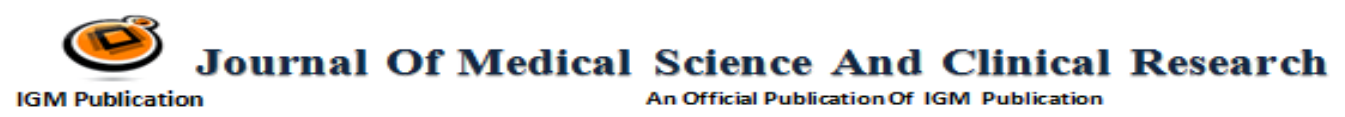

\title{
Study of the Incidence of Diabetic Retinopathy in Patients with Type 2 Diabetes Mellitus and Ischeamic Heart Disease
}

(Original Article)

\author{
Authors \\ Dr Debapriya Datta, Dr O K Radhakrishnan, Dr Madhuri Sarkar, Dr Priti \\ Corresponding Author \\ Dr Debapriya Datta \\ Email: debapriya87@gmail.com, Mobile:9764113797
}

\begin{abstract}
Introduction: Diabetes mellitus (DM) is a metabolic disorder characterised by raised blood glucose level and diabetic retinopathy is a vascular disorder which affects the microvasculature of the retina. Diabetic retinopathy can occur in both type 1 and type 2 DM. Type 2 DM is a very important independent risk factor for development of cardiovascular disease, stroke, peripheral arterial disease, cardiomyopathy and congestive heart failure $(\mathrm{CHF})$. These macrovasular complications are one of the leading causes of deaths in the world. The impact of glycaemic control in reducing micro vascular complications has been well established. Although controversial, there is evidence that glycaemic control can limit macrovasular disease including cardiovascular disease, stroke and peripheral arterial disease.

The purpose of doing the study is to find out if there is a greater occurrence of Ischaemic Heart Disease (IHD) in patients of diabetic retinopathy and if the more severe stages of diabetic retinopathy are associated with increased occurrence of IHD. Since IHD is a macrovascular complication of DM and diabetic retinopathy is a microvascular complication of DM, we would like to know if there is a correlation between the two.

Aims And Objective

1. Study the incidence of diabetic retinopathy in patients with type $2 D M$

2. Study the incidence of diabetic retinopathy in patients with type 2 DM and ischemic heart disease

3. Establish relationship between diabetic retinopathy and ischemic heart disease 4. Establish if DR is a valid predictor of ischemic heart disease

Materials And Method: A cross sectional observational study was conducted in Padmashree. DR. D. Y. Patil medical college, hospital and research center, Pimpri, Pune after the approval by institutional ethical committee. A total of 320 patients were studied.

Inclusion criteria Patients of age between 40 to 70 years with h/o type 2 DM for at least 5 years duration and ECG evidence of IHD.

Exclusion criteria patients with any other systemic illness, patients with hazy media preventing visualisation of fundus, myopia, h/o eye surgery, h/o laser photocoagulation or any other ocular pathology.

The selected patients were divided into 2 groups:

Group A: 50 eyes of type 2 DM with diabetic retinopathy but without IHD

Group B:50 eyes of type 2 DM with diabetic retinopathy and with IHD

HBAIC, blood urea, serum creatinine, serum lipids and BP was recorded for all patients.

Conclusion: In our study, we found the incidence of diabetic retinopathy to be 14.2\%.there was no significant
\end{abstract}


difference in the types of retinopathy between the two study groups. there was no significant difference between sex distributions in both groups. there was no significant difference in age amongst the two groups.

Keywords: Diabetic retinopathy, Type 2 diabetes mellitus, Ischaemic heart disease, blood glucose, HbAlc

\section{INTRODUCTION}

Diabetes mellitus (DM) is a metabolic disorder characterised by raised blood glucose level. DM affects about $4 \%$ of the world's population , $50 \%$ of whom have some degree of diabetic retinopathy at some given point of time. ${ }^{(1)}$ Diabetic retinopathy affects the microvasculature of the retina and can occurs in both type 1 and type 2 $\mathrm{DM}$. Some epidemiological studies show that nearly $100 \%$ of type 1 and $75 \%$ of type $2 \mathrm{DM}$ will develop diabetic retinopathy in 15 yrs duration of diabetes. $^{(2,3)}$ In India, with the increasing incidence of type $2 \mathrm{DM}$ as reported by WHO, diabetic retinopathy is becoming a fast and important cause of visual disability, which is a significant public health problem. However this morbidity is largely preventable with timely intervention. $^{(4)}$

The prevalence of diabetes mellitus in Asia is predicted to increase from 240 million in 2007 to 380 million in $2025 .{ }^{(5)}$ Effective evidence based strategies are needed to reduce the significant morbiditiy and burden imposed by diabetes. ${ }^{(6)}$

Type 2 DM has been recognised as an independent risk factor for cardiovascular disease, stroke, congestive heart failure (CHF) and peripheral arterial disease. These macrovasular complications are one of the leading causes of deaths in the world. The importance of glycaemic control in reducing micro vascular complications is well established. Although controversial, there is evidence that glycaemic control can limit macrovasular disease including cardiovascular disease, stroke and peripheral arterial disease. ${ }^{(9)}$

Hemodynamic (impaired auto regulation and hyper perfusion) and VEGF are the possible mechanisms by which hypertension may affect DR. The hypothesis was supported by observations from clinical study which showed association between CHD and the presence and severity of DR in diabetic people..$^{(7,8)}$
The purpose of doing the study is to find out the incidence of Ischaemic Heart Disease (IHD) in patients of diabetic retinopathy and also to know if more severe stages of diabetic retinopathy is associated with increased occurrence of IHD.

To find out the correlation between IHD and diabetic retinopathy since IHD is a macrovascular complication of DM and diabetic retinopathy is a microvascular complication of DM.

\section{AIMS AND OBJECTIVE}

1. Study the incidence of diabetic retinopathy in patients with type $2 \mathrm{DM}$

2. Study the incidence of diabetic retinopathy in patients with type $2 \mathrm{DM}$ and ischemic heart disease

3. Establish relationship between diabetic retinopathy and ischemic heart disease

4. Establish if DR is a valid predictor of ischemic heart disease

\section{MATERIALS AND METHOD}

After the approval by institutional ethical committee, study was conducted in Padmashree. DR. D. Y. Patil medical college, hospital and research center, Pimpri, Pune

Study design: it was a cross sectional observational study

Study site: the study was carried out on the patients attending ophthalmology OPD.

Inclusion criteria Patients of age between 40 to 70 years with h/o type $2 \mathrm{DM}$ for at least 5 years duration and ECG evidence of IHD.

Exclusion criteria patients with any other systemic illness, patients with hazy media preventing visualization of fundus, myopia, h/o eye surgery, h/o laser photocoagulation or any other ocular pathology.

Sample size: a total of 50 patients were studied 


\section{THE SELECTED PATIENTS WERE DIVIDED INTO 2 GROUPS:}

Group A: 50 eyes of type $2 \mathrm{DM}$ with diabetic retinopathy but without IHD

Group B: 50 eyes of type $2 \mathrm{DM}$ with diabetic retinopathy and with IHD

HBA1C, blood urea, serum creatinine, serum lipids and BP was recorded for all patients.

Sampling technique: data was collected by questionaires and clinical examination (profoma attached)
Data entry and statistical analysis: after the collection of data the results were tabulated and analysed.

\section{OBSERVATIONS AND RESULTS}

1. Total number of patients observed were 320 .

2. All of them had type $2 \mathrm{DM}$ of minimum 5 years duration.

3. 50 of such patients were found to have DR on fundus examination.

Calculation of the incidence of DR in pts with type $2 \mathrm{DM}$

No. of eyes with DR $\times 100=\underline{100} \times 100=14.2 \%$ (at $95 \%$ confidence interval)

Total no. of eyes observed $\quad 640$

Table 1 - Distribution of different factors and their relationship in study groups

\begin{tabular}{|c|c|c|c|c|}
\hline Type of DR & GROUP 1 & GROUP 2 & Total & $P$ value \\
\hline PDR & 10 & 6 & 16 & \multirow[t]{3}{*}{0.225253} \\
\hline NPDR & 15 & 19 & 34 & \\
\hline Total & 25 & 25 & 50 & \\
\hline \multicolumn{5}{|l|}{ Gender } \\
\hline Male & 9 & 8 & 17 & \multirow[t]{3}{*}{0.7625291} \\
\hline Female & 16 & 17 & 33 & \\
\hline Total & 25 & 25 & 50 & \\
\hline \multicolumn{5}{|l|}{ Age (in years) } \\
\hline $40-50$ & 2 & 1 & 3 & \multirow[t]{4}{*}{0.473258} \\
\hline $50-60$ & 8 & 5 & 13 & \\
\hline $60-70$ & 15 & 19 & 34 & \\
\hline Total & 25 & 25 & 50 & \\
\hline \multicolumn{5}{|c|}{\begin{tabular}{lr|r}
$\begin{array}{l}\text { Duration } \\
\text { diabetes }\end{array}$ & of & (in \\
years) & &
\end{tabular}} \\
\hline $5-10$ & 1 & 1 & 2 & \multirow[t]{7}{*}{0.900006} \\
\hline $10-15$ & 1 & 1 & 2 & \\
\hline $15-20$ & 2 & 3 & 5 & \\
\hline $20-25$ & 5 & 7 & 12 & \\
\hline $25-30$ & 6 & 7 & 13 & \\
\hline$>30$ & 10 & 6 & 16 & \\
\hline Total & 25 & 25 & 50 & \\
\hline \multicolumn{5}{|l|}{$\begin{array}{l}\text { Use of oral } \\
\text { hypoglycaemic } \\
\text { agent }\end{array}$} \\
\hline $\begin{array}{l}\text { Patients taking } \\
\text { medications }\end{array}$ & 3 & 5 & 42 & \\
\hline $\begin{array}{ll}\text { Patients not } \\
\text { taking } \\
\text { medications }\end{array}$ & 22 & 20 & 8 & \\
\hline
\end{tabular}




\begin{tabular}{|c|c|c|c|c|}
\hline Total & 25 & 25 & 50 & \\
\hline \multicolumn{5}{|c|}{$\begin{array}{l}\mathrm{BSL} \text { value in } \\
\mathrm{mg} / \mathrm{dl}\end{array}$} \\
\hline $200-250$ & 1 & 2 & 3 & \multirow[t]{5}{*}{0.044084} \\
\hline $250-300$ & 4 & 3 & 7 & \\
\hline $300-350$ & 10 & 18 & 28 & \\
\hline$>350$ & 10 & 2 & 12 & \\
\hline Total & 25 & 25 & 50 & \\
\hline \multicolumn{5}{|c|}{$\begin{array}{l}\text { Blood pressure } \\
(\mathrm{mmHg})\end{array}$} \\
\hline Systolic & $143.1+/-4.6$ & $142.2+/-4.5$ & & \multirow[t]{2}{*}{0.93154} \\
\hline Diastolic & $90.78+/-1.1$ & $91.69+/-2.9$ & & \\
\hline \multicolumn{5}{|c|}{$\begin{array}{l}\text { Serum } \\
\text { cholesterol } \\
\text { levels }(\mathrm{mg} / \mathrm{dl})\end{array}$} \\
\hline$<200$ & 16 & 0 & 16 & \multirow[t]{4}{*}{0.0000018} \\
\hline $200-250$ & 7 & 5 & 12 & \\
\hline$>250$ & 2 & 20 & 22 & \\
\hline Total & 25 & 25 & 50 & \\
\hline \multicolumn{5}{|c|}{ Sr. triglyceride } \\
\hline$<180 \mathrm{mg} / \mathrm{dl}$ & 16 & 2 & 18 & \multirow[t]{3}{*}{0.00012} \\
\hline$>180 \mathrm{mg} / \mathrm{dl}$ & 9 & 22 & 31 & \\
\hline Total & 25 & 25 & 50 & \\
\hline \multicolumn{5}{|l|}{$\begin{array}{l}\text { Low density } \\
\text { lipoprotein } \\
\text { (LDL) } \\
(\mathrm{mg} / \mathrm{dl})\end{array}$} \\
\hline$<100$ & 10 & 0 & 10 & \multirow[t]{4}{*}{0.00008} \\
\hline $100-190$ & 9 & 5 & 14 & \\
\hline$>190$ & 6 & 20 & 26 & \\
\hline Total & 25 & 25 & 50 & \\
\hline \multicolumn{5}{|c|}{$\begin{array}{l}\text { Sr. high density } \\
\text { lipoprotein } \\
\text { ( LDL) }\end{array}$} \\
\hline $30-60 \mathrm{mg} / \mathrm{dl}$ & 16 & 2 & 18 & \multirow[t]{3}{*}{0.00008} \\
\hline$>60 \mathrm{mg} / \mathrm{dl}$ & 22 & 9 & 31 & \\
\hline Total & 25 & 25 & 50 & \\
\hline \multicolumn{5}{|c|}{$\begin{array}{l}\text { HbA1c levels } \\
(\mathrm{mg} \%)\end{array}$} \\
\hline $5.6-6.4$ & 6 & 0 & 6 & \multirow[t]{4}{*}{0.0045} \\
\hline $6.5-7.3$ & 9 & 5 & 14 & \\
\hline$>7.3$ & 10 & 20 & 30 & \\
\hline Total & 25 & 25 & 50 & \\
\hline
\end{tabular}

Table 2 - Comparison of the severity and types of retinopathy with the occurrence of IHD

\begin{tabular}{|l|l|l|l|}
\hline Evidence of IHD & PDR & NPDR & Total \\
\hline Present & 20 & 5 & 25 \\
\hline Absent & 12 & 13 & 25 \\
\hline Total & 32 & 18 & 50 \\
\hline
\end{tabular}




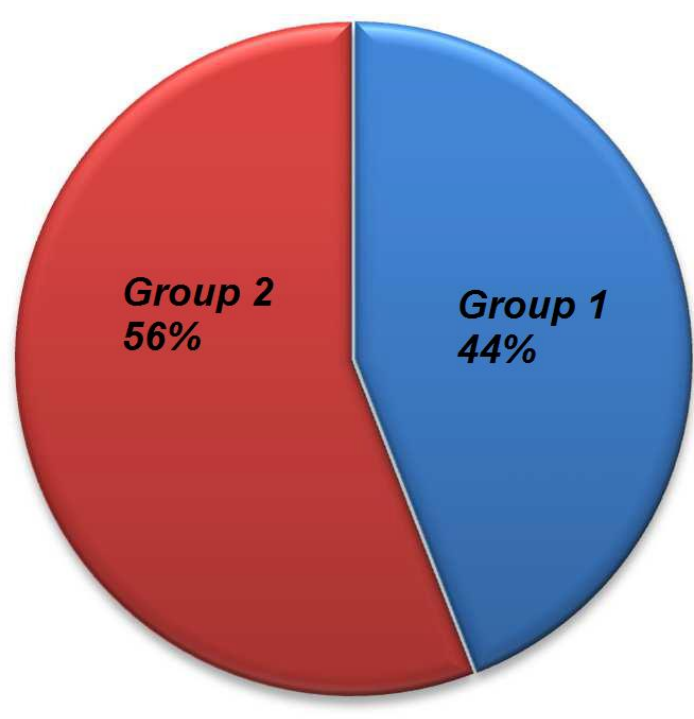

Fig 1 - Occurrence of NPDR in both groups

\section{DISCUSSION}

The presence of signs of retinopathy in individuals with type 2 diabetes has been shown to be associated with two fold higher risk of incident CHD and threefold higher risk of fatal CHD, independent of glycaemic levels, cardiovascular risk factors and large vessel atherosclerosis. This association appears to be graded with severity of retinopathy and was found to be significant in men and women, even when not associated with hypertension. It appears that micro vascular disease may contribute to the development of CHD in people with diabetes. ${ }^{(14)}$

Though mild retinopathy does not significantly reduce vision, it is associated with the odds of having or developing cardiovascular diseases like heart attack and stroke, as well as the risk of dying from these conditions. Patients who develop even mild retinopathy should be considered for preventive care beyond that offered to patients with diabetes without retinopathy (e.g. tighter blood glucose, blood pressure and blood lipid control, additional diabetes education, more frequent follow-up and assessment of cardiovascular health, etc).

We found the incidence of diabetic retinopathy to be $14.2 \%$ in our study, which was similar to the results of the atherosclerosis risk in community study which found it to be $14.7 \% .^{(14)}$

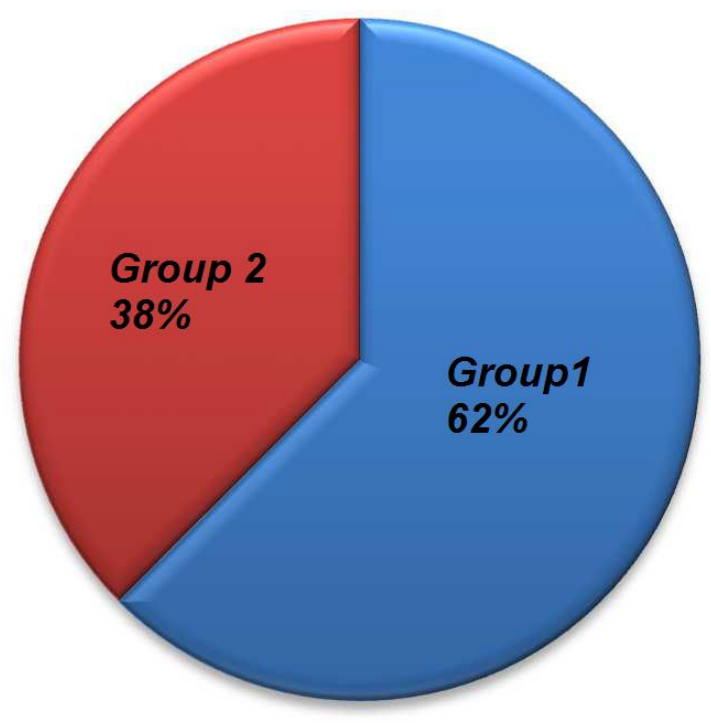

Fig 2 - Occurrence of PDR in both groups

In our study there was no significant difference in the types of retinopathy between the two study groups. Our findings match with the study by Egyptian Society of Cardiology. ${ }^{(13)}$

There was no significant difference between sex distributions in both groups in our study. A clinic cohort in Chennai found that DR is more prevalent in males than in females (ratio2:1). ${ }^{(7)}$

In our study there was no significant difference in age amongst the two groups. Our findings correlate with a study conducted in Chennai. ${ }^{(7)}$

In our study there was no significant difference in duration of diabetes in both the study groups. This co relates with a study conducted in Chennai. ${ }^{(7)}$

In our study there was no significant difference in blood sugar levels between the 2 study groups. This co relates with a study conducted in Chennai. ${ }^{(7)}$

Our study showed no significant difference in both groups with regard to blood sugar levels unlike the UKPDS study which showed higher blood sugar levels to be associated with a higher grade of DR. ${ }^{(12)}$ This difference could be due to the small sample size in our study.

There was no significant variation in blood pressure amongst the two Groups in our study. However the CURES eye study found that uncontrolled hypertension did influence the progression of DR. ${ }^{(10)}$ 
There was significant variation in serum cholesterol, triglycerides, LDL and HDL levels between the two groups in our study, which is similar to the findings of the Egyptian Society of Cardiology ${ }^{(13)}$, ETDRS study ${ }^{(15)}$ and the WESDR study. ${ }^{(11)}$

There was a strong association between HbAlc levels in patients with both DR and IHD than in patients with DR alone in our study which are similar to the findings of the CURES eye study. ${ }^{(10)}$ Our study also found that the occurrence of proliferative DR was more common in patients with IHD which is similar to the findings the Egyptian Society of Cardiology (23) and the atherosclerosis risk in community study. ${ }^{(14)}$

\section{CONCLUSION}

This study tells us that the severity of diabetic retinopathy in patients with Type $2 \mathrm{DM}$ correlates with the risk of a patient developing IHD. Cardiovascular physicians should be aware of important relationship between diabetic retinopathy and IHD and be prepared to institute appropriate treatment to reduce disability and deaths in these patients.

\section{REFERENCES}

1. Aiello LP, Gardner TW, King GL, Blankenship G, Cavallerano JD, Ferris FL 3rd, et al. Diabetic retinopathy. Diabetes Care 1998; 21 : 143-56.

2. Klein R, Klein BE, Moss SE, Davis MD, DeMets DL. The Wisconsin Epidemiologic Study of Diabetic Retinopathy. II. Prevalence and risk of diabetic retinopathy when age at diagnosis is less than 30 years. Arch Ophthalmol 1984; $102: 520-6$.

3. Klein R, Klein BEK, Moss SE, Davis MD, DeMets DL. The Wisconsin epidemiologic study of diabetic retinopathy III. Prevalence and risk of diabetic retinopathy when age at diagnosis is 30 or more years. Arch Ophthalmol 1984; 102 : 527-32.
4. Wild S, Roglic G, Green A, Sicree R, King H. Global prevalence of diabetes, estimates for the year 2000 and projections for 2030. Diabetes Care 2004; 27 : 1047-53.

5. Chan J C, Malik V, Jia W et al. diabetes in asia: epidemiology, risk factors and pathophysiology. JAMA 2009;301(20): 2129-2140

6. Mohamed Q, Gillies M C, Wong $\mathrm{T}$ Y. management of diabetic retinopathy: a systemic review, JAMA 2007; 298(8):902916

7. Rema M, Sujatha P, Pradeepa R. Visual outcomes of panretinal photocoagulation in diabetic retinopathy at one-year followup and associated risk factors. Indian $J$ Ophthalmol 2005; 53 : 93-9.

8. Kohner EM. Diabetic retinopathy. $\mathrm{Br}$ Med Bull 1989; 45 : 148-73.

9. Hertzel $\mathrm{C}$ et al. diabetic retinopathy, its progression, and incident cardiovascular events in the ACCORD trail. USA 2013; 2337(10):dc12-12311

10. Rema M, Premkumar S, Anitha B, Deepa R, Pradeepa R, Mohan V. Prevalence of diabetic retinopathy in urban India: The Chennai Urban Rural Epidemiology Study (CURES) Eye Study, I. Invest Ophthalmol Vis Sci 2005; 46 : 2328-33

11. Klein R, Davis MD, Moss SE, Klein BE, DeMets DL. The Wisconsin Epidemiologic Study of Diabetic Retinopathy (WEDSR). A comparison of retinopathy in younger and older onset diabetic persons. Adv Exp Med Biol 1985; $189: 321-35$.

12. UK Prospective Diabetes Study (UKPDS) Group. Intensive blood-glucose control with sulphonylureas or insulin compared with conventional treatment and risk of complications in patients with type 2 diabetes (UKPDS 33). Lancet 1998; 352 : 837-53.

13. Fawzia El Demerdash, Wael Refaie, Rashid Allakany, Salah Tantawy, Eid 
Dawood : Diabetic Retinopathy: a predictor of coronary heart disease. 2011. 08.006

14. Ning Cheung, Jin Jin Wang, Ronald Klein, David J Couper, A. Richey Sharrett, Tein Y. Wong : Diabetic Retinopathy and the risk of Coronary Heart Disease. Diabetes care :July 2007 vol. 30 no. 7: 1742-1746

15. Ferris FL 3rd, Chew KY, Hoogwerf BJ. Serum lipids and diabetic retinopathy. Early Treatment Diabetic Retinopathy Study Research Group ( EDTRS) . Diabetes Care 1996; 19 :1291-3. 